\title{
Automatic Ultrasonic Testing System Designed For Small- Diameter Steel Pipes With Thick Wall
}

\author{
Qi Zhang ${ }^{*}, 1,2$, Li Hou ${ }^{2}$ and Rui Tang ${ }^{2}$ \\ ${ }^{1}$ School of Manufacturing Science and Engineering, Sichuan University, \\ Chengdu, 610065, China, \\ ${ }^{2}$ School of Machinery and Engineering, Panzhihua University, Panzhihua, \\ 617000, China,
}

\begin{abstract}
In this paper, the detection of small-diameter steel pipes with thick wall using ultrasonic immersion method with focusing probe was presented. The transmission paths were chosen, which were based on selected thick steel pipes $(t / D \geq 0.3)$, so-called converted shear wave testing method of ultrasonic detection of flaws. Moreover, the sound pressure of echo of flaws detected by converted shear wave was deduced. A PCbased microcomputer water immersion all digital multi-channel automatic ultrasonic testing system is designed. Experimental results showed that it was feasible to detect the flaw by using the designed system. Automatic ultrasonic flaw detection equipment for small-diameter steel pipes with thick wall, based on theory of converted shear wave, could be applied to aerospace industry, nuclear power equipment manufacturers, special equipment manufacturing industry and other industries. It has great practical application value and market prospects.
\end{abstract}

Keywords: Ultrasonic flaw detection, Non-destructive Testing (NDT), pulse reflection method, thick-walled tube, wave-type conversion

\section{Introduction}

The seamless pipe has a wide application. It has the diameter size of $10 \mathrm{~mm} 3000 \mathrm{~mm}$ and wall thickness of $2 \mathrm{~mm} \sim 60 \mathrm{~mm}$ and can work under the situation of high temperature and high pressure. The small caliber seamless steel pipe with thick wall, having diameter usually less than $50 \mathrm{~mm}$ and wall thickness less than $4-12 \mathrm{~mm}$ [1], usually is made by perforation method and high-speed extrusion method. Its common quality defects are lamination, inclusion, double skin and crack [2].

Many flaws or cracks detects techniques have been applied into our industry, such as the X-rays [3] ,Ultrasonic inspection, Radiographic inspection, Magnetic particle inspection, Penetrant inspection, Acoustic emission inspection ,Magnetic flux leakage inspection and so forth [4]. The use of ultrasonic pulse-echo techniques to find flaws or cracks in pipes has become widespread in pipe manufacturers [5]. The automation of this process has facilitated collection of large quantities of data [6]. However, this method is generally applicable to inspect the defects of the pipes, of which the t/D ratio is less than 0.26 . The so-called $t / \mathrm{D}$ ratio is the thickness-outer-radius ratio of pipes. When processing the Ultrasonic flaw detection of the steel pipe, if $t / D>0.26$, it is impossible to realize the flaw detection of the pipe's whole cross section, because the transversal wave beam can't scan and find defects in steel pipe's inner wall when performing pure transversal wave crack detection. Therefore, the inspection quality of inner wall of steel pipe whose t/D ratio is greater than 0.26 , is considered as the "closed area" of ultrasonic testing of the steel pipe. 
In this paper, the detection of small diameter steel pipes with thick wall using ultrasonic immersion method with focusing probe was adopted. Ultrasonic immersion method with focusing probe was advantageous for increasing the scan speed of ultrasonic testing and shortening test time. It was especially beneficial for overall-length and allround detection [7].It was difficult to apply pure shear wave to detect the flaws of pipes, so longitudinal wave oblique incidence method and converted shear wave testing method was considered [8]. Converted shear wave testing method is suitable for the pipes whose ratio of wall thickness to size t/D was more than 0.23 . When detecting defects used longitudinal wave oblique incidence method, there were many shortcomings. For example, Aliasing of refracted longitudinal wave and refracted transverse wave occurred. Echo was much more complex. Longitudinal wave oblique incidence method had lower detection sensitivity because of lower energy of the refracted longitudinal wave.

In this paper, the way of flaw detection of the small-diameter steel pipes with thick wall, of which the t/D ratio is more than 0.26 , was studied. The sound pressure of echo of flaws detected by converted shear wave was deduced. A PC-based microcomputer water immersion all digital multi-channel automatic ultrasonic testing system is designed based on them. Experimental results showed that it was feasible to detect the flaw of the small diameter steel pipes with thick wall by this system.

\section{Detection Theory}

\subsection{Detection Principle}

The outer flaw can be detected by using the refracted longitudinal waves. It was difficult to apply pure shear wave to detect the inner flaws of pipes, so a converted shear wave testing method was considered to inspect it (shown in Figure 1).

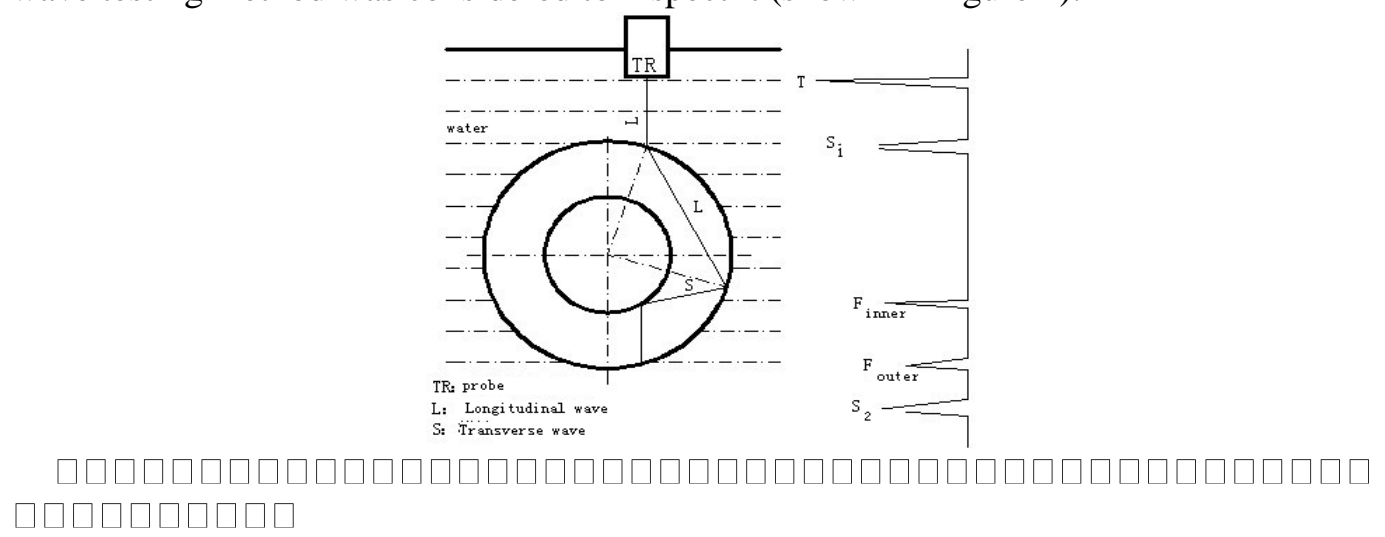

Figure 1. Principle to Detect the Longitudinal Defects

$\mathrm{T}$-beginning wave $\mathrm{S}_{1}$-nterfacial wave, $\mathrm{F}_{\text {inner }}-$ inner wall defects wave, $\mathrm{F}_{\text {outer }}$ - outer wall defects wave, $\mathrm{S}_{2}$-nterfacial wave

The principle to detect the defects of the circumferential direction of the thick-walled steel pipe is shown in Figure 2. 


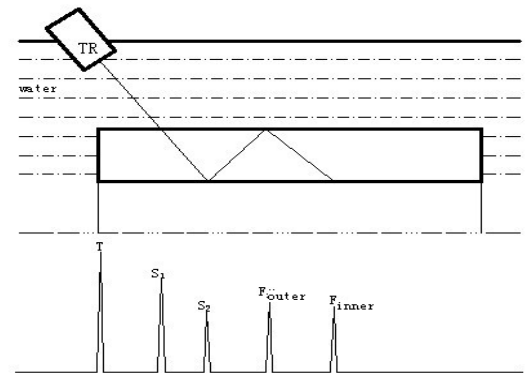

Figure 2. Principle to Detect the Defects of the Circumferential Direction

\subsection{Choice of Detection Route}

The ultrasonic wave simultaneously disseminates the longitudinal wave and the transversal wave in the solid media. When using the water immersion ultrasonic crack detection method, the ultrasonic incidence wave from water into steel would produce waves of different wave modes, longitudinal and transverse waves, as the different incidence angles. When the ratio of wall thickness to diameter of the pipe $t / D>0.2239$, the pure transverse wave testing method can't detect the flaw of inner wall of the pipe, because the shear wave can't arrive the inner wall of the steel pipe. With regards to thickwalled steel pipes, which have a ratio of wall thickness to diameter $t / D>0.2239$, we used the method of wave modes conversion of incident to detect flaws by making incident angle $\alpha$ less than the critical angle $\alpha$ I $\left(14.655^{\circ}\right)$. When the incident angle $\alpha<14.655^{\circ}$, the ultrasonic wave enter the tube propagate both transverse wave and longitudinal wave, so with the different probe eccentricity, the route of wave propagation in the pipe is dissimilar. For example, let's take a look at the $\Phi 20 \times 6$ (diameter is $20 \mathrm{~mm}$, wall thickness of $6 \mathrm{~mm}$ ) steel pipe. When the incidence angle $\alpha$ is in the domain [10.561 ${ }^{\circ}$, $\left.14.655^{\circ}\right]$, wave dissemination route in ultrasonic detection system was shown in Figure $3[7,8,9]$.

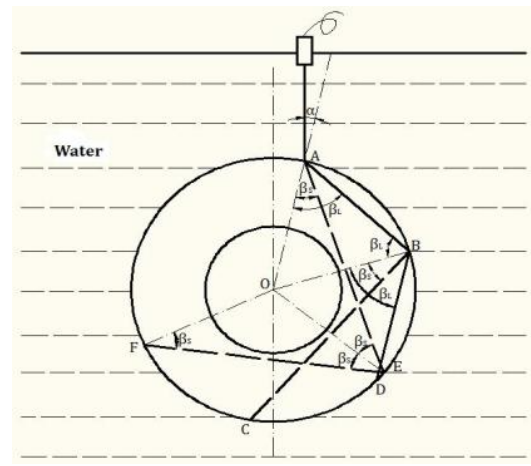

Figure 3. Wave Dissemination Route with Incidence Angle Range [10.561 ${ }^{\circ}$, $\left.14.655^{\circ}\right]$

According to the Snell theorem and the geometric relationships shown in Figure 3, we known that:

$$
\left\{\begin{array}{l}
\beta_{s}: \sin ^{-1}\left(\left(C_{S 2} \times \sin \alpha\right) / C_{L 1}\right) \\
\beta_{s}: \sin ^{-1}\left(\left(C_{L 2} \times \sin \alpha\right) / C_{L 1}\right) \\
\alpha_{s 1}: \sin ^{-1}\left(\left(R \times \sin \beta_{s}\right) / r\right)
\end{array}\right.
$$

where, CL1 $=$ the longitudinal wave velocity in water, CL2 $=$ the longitudinal wave velocity in steel, $\mathrm{CT} 2=$ the transverse wave velocity in steel, $\mathrm{R}=$ the outer diameter of steel pipe, $r=$ the inner diameter of steel pipe. 


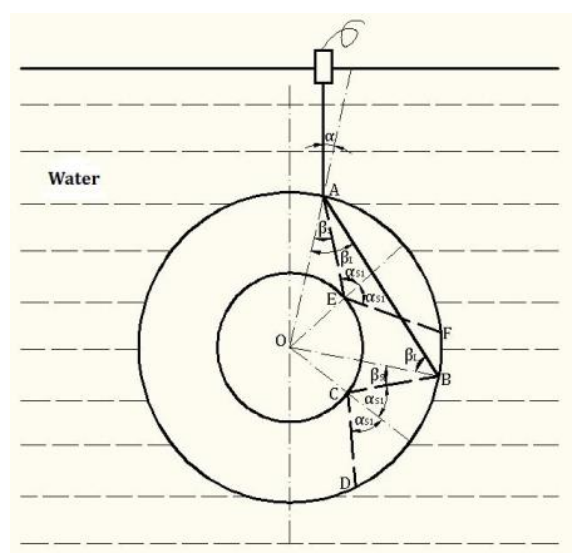

\section{Figure 4. Wave Dissemination Route with Incidence Angle Range [5.808 $\left.10.561^{\circ}\right]$}

It can be seen from fig. 6 that the refracted transverse wave can't contact the inner wall of steel pipe and only reflects on the outer wall of steel pipe. Refracted longitudinal wave place has a mode conversion at the point $\mathrm{B}$ in outer wall of the steel pipe producing a reflected transverse wave and a reflected longitudinal wave. The reflected transverse wave and the reflected longitudinal wave can't achieve the inner wall of steel pipe. They directly arrive at the points $\mathrm{C}$ and $\mathrm{D}$ in outer wall of the steel pipe respectively. Therefore this incidence angle range can't be used to detect flaws in the small-diameter steel pipe with thick wall. When the incidence angle $\alpha$ is in the domain $\left[5.808^{\circ}, 10.561^{\circ}\right]$, wave dissemination route in ultrasonic detection system was shown in Figure 4.

When the incident angle $\alpha$ between interval $\left[5.808^{\circ}, 10.561^{\circ}\right)$, the incident longitudinal wave in the water, transmitting itself into steel pipe at point $\mathrm{A}$, has the mode conversion. This wave mode conversion produces a refracted longitudinal wave and a refracted transverse wave at the same time. The refracted angle $\beta S$ of the refracted transverse wave was in the interval $\left[12.759^{\circ}, 23.578^{\circ}\right)$. This refracted transverse wave's transmission line is A-E -F, where AE and EF are transverse waves. The refracted angle $\beta \mathrm{L}$ of the refracted longitudinal wave was in the interval $\left[23.578^{\circ}, 46.424^{\circ}\right)$. This refracted longitudinal wave's transmission line is $\mathrm{A}-\mathrm{B}-\mathrm{C}-\mathrm{D}$, where $\mathrm{AB}$ is a longitudinal wave, $\mathrm{AE}$ and $\mathrm{EF}$ are transverse waves. The wave at the point $\mathrm{B}$ has a mode conversion, transmitting the wave into another reflected transverse wave and reflected longitudinal wave. The reflected longitudinal wave can't achieve the inner wall of steel pipes and not detect the crack of the inner wall of steel pipes. The reflected transverse wave continues to transmit and arrives the point $C$. The wave was entirely reflected at the point $C$ (a point of steel-air interface) and then didn't have the wave-mode conversion.

When the incidence angle $\alpha$ is in the domain $\left[5.808^{\circ}, 10.561^{\circ}\right]$, the incident longitudinal wave in the water has the mode conversion, producing the refracted transverse wave and the refracted longitudinal wave. Although the two kinds of waves can survey the flaws in inner wall of steel pipes, the echo sound pressure of defects is unknown and is separately discussed as below. Refracted transverse wave's propagating route was shown in Figure 5. 


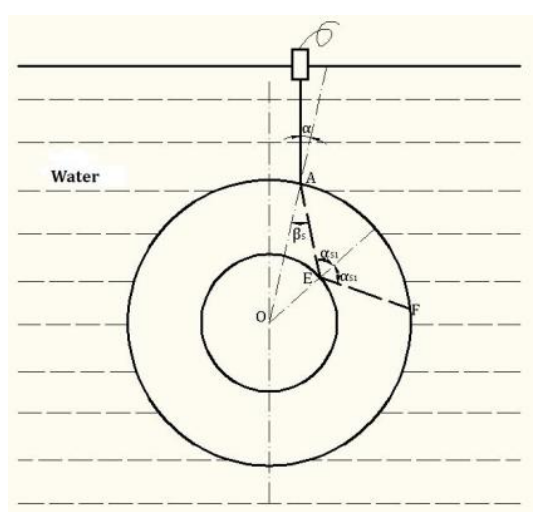

Figure 5. Wave Dissemination Route of the Refracted Transverse Wave

Applying the above theories to resulting in the sound pressure of steel pipes, the echo sound pressures of flaws at the point $\mathrm{E}$ and $\mathrm{F}$ must be depicted as below.

$$
\begin{gathered}
P_{E}=D_{L T}(\text { water }- \text { steel }) \times D_{T L}(\text { steel }- \text { water }) \\
P_{F}=D_{L T}(\text { water }- \text { steel }) \times D_{T L}(\text { steel }- \text { water }) \\
\\
\times R_{T T}^{2}(\text { steel }- \text { air })
\end{gathered}
$$

Refracted longitudinal wave's propagating route was shown in Figure 6.

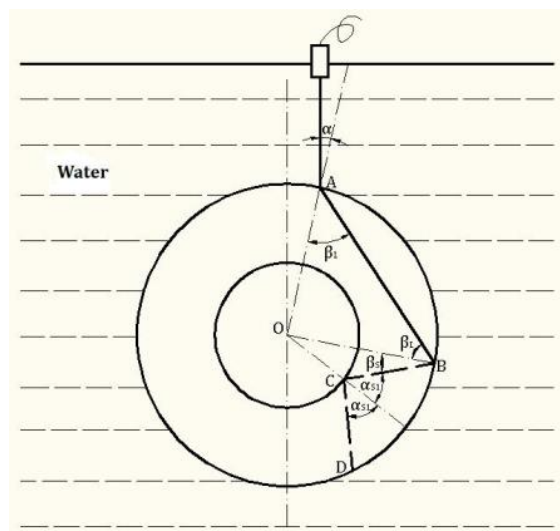

Figure 6. Wave Dissemination Route of the Refracted Longitudinal Wave

Applying the above theories to resulting in the sound pressure of steel pipes, the echo sound pressures of flaws at the point $\mathrm{C}$ and $\mathrm{D}$ must be depicted as below.

$$
\begin{gathered}
P_{C}=D_{L L}(\text { water }- \text { steel }) \times R_{L T}(\text { steel }- \text { water }) \times \\
R_{T L}(\text { steel }- \text { water }) \times D_{L L}(\text { steel }- \text { water }) \\
P_{D}=D_{L L}(\text { water }- \text { steel }) \times R_{L T}(\text { steel }- \text { water }) \times R_{T L}(\text { steel } \\
- \text { water }) \times D_{L L}(\text { steel }- \text { water }) \times R_{T T}^{2}(\text { steel }- \text { air })
\end{gathered}
$$

The sound pressure ratio of flaws of the inner pipe, which are detected by refracted longitudinal wave and refracted transverse wave respectively, is

$$
H_{I}=\frac{P_{C}}{P_{B}}
$$

The sound pressure ratio of flaws of the outer pipe, which are detected by refracted longitudinal wave and refracted transverse wave respectively, is 


$$
H_{0}=\frac{P_{D}}{P_{F}}
$$

Substituting (2) and (4) into (6), (3) and (5) into (7), we can obtain

$$
\begin{aligned}
H_{I}=H_{0}= & \frac{D_{L L}(\text { water }- \text { steel }) \times R_{L T}(\text { steel }- \text { water })}{D_{L T}(\text { water }- \text { steel }) \times D_{T L}(\text { steel }- \text { water })} \times \\
& R_{T L}(\text { steel }- \text { water }) \times D_{L L}(\text { steel }- \text { water })
\end{aligned}
$$

and it was shown in Figure 7.

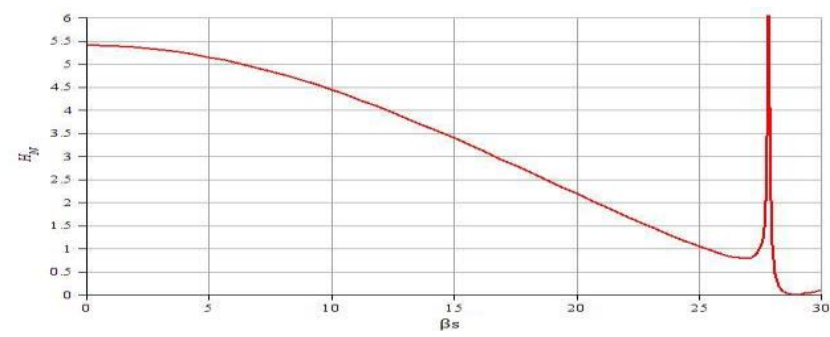

Figure 7. The Sound Pressure Ratio of Flaws of the Inner and Outer Pipe

Known from Figure 7, when the incidence angle $\alpha$ is in the domain $\left[5.808^{\circ}, 10.561^{\circ}\right.$, the refracted angle $\beta S$ of the refracted transverse wave was in the interval $\left[12.759^{\circ}\right.$, $23.578^{\circ}$ ). And then HI reduces with $\beta \mathrm{S}$ increases. When the crack detecting in practice, using this angle range was possible to maximize the wave height of flaws and improve the signal-to-noise ratio of supersonic echo signal in the same noise situation.

\section{System Design}

\subsection{Components of Testing System}

When manually detecting the flaws of small-diameter steel pipes with thick wall, the examination efficiency is very low and the intensity of labor is big. Therefore manual examination is suitable merely for the single-piece and small-batch and multispecification tubing examination. In order to realize the batch examination of the smalldiameter steel pipes with thick wall, we developed an experimental equipment, automatic crack detection system (shown in Figure 8).

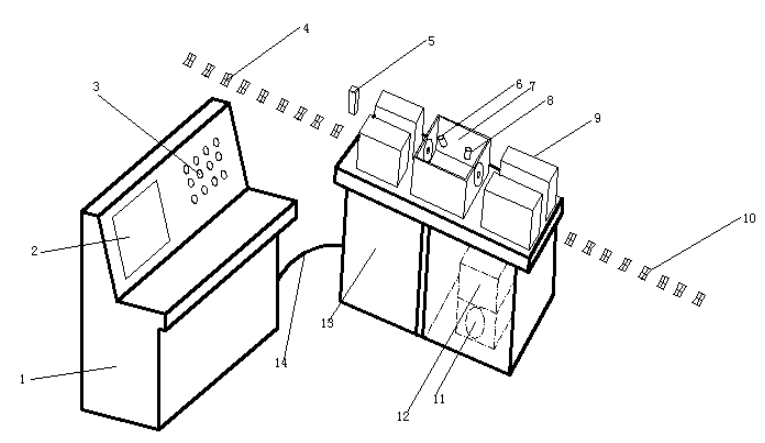

Figure 8. Diagram of the Designed Automatic Ultrasonic Flaw Detection System

1-Control cabinet 2-LCD monitor 3-Control buttons 4-Pipe output mechanism 5-spray mechanism 6- Transverse flaw probe 7-water box 8-Longitudinal flaw probe 9- Steel tube feeding device 10-Pipe input mechanism 11-DC motor 12Storage tanks13-Testing work platform 14-Control bus 
This system is composed of multichannel supersonic instrumentation and mechanical drive system. The salience characteristic of mechanical drive system is that probe is fixed and the tubing is rotating forward. This typical PC-based ultrasonic flaw detection system is set up as shown in Figure 9.

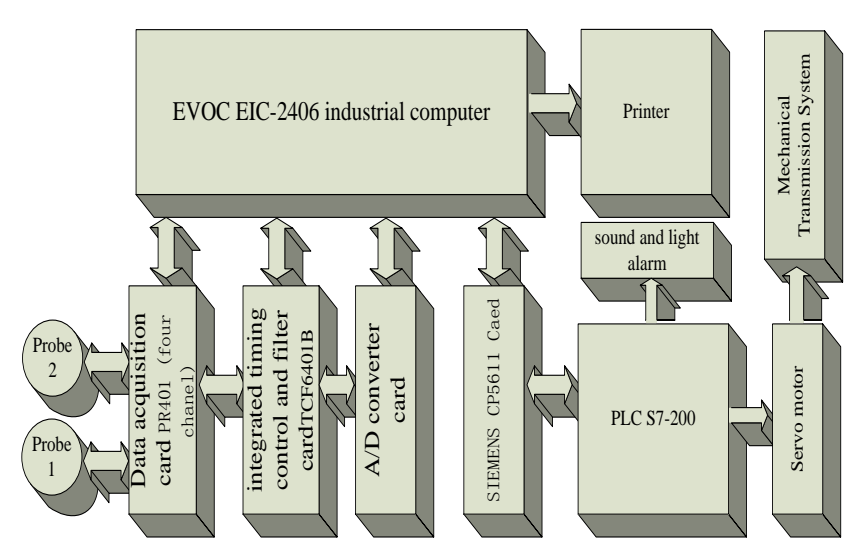

Figure 9. PC-Based Automatic Ultrasonic Flaw Detection Systems

Our experiment used line focused probe (SIR5-03), products of the U.S. Pan-Pacific Automation Instrument Corporation. The carrier frequency and bandwidth of the transducers are $5 \mathrm{MHz}$ and $1.5 \mathrm{MHz}$, respectively. A regular small-diameter steel pipe with thick wall is used as the specimen. The wall thickness of the specimen, which diameter is $50 \mathrm{~mm}$, is $12 \mathrm{~mm}$, and the depth of the outside surface cracks and inside surface cracks is $1 \mathrm{~mm}$. EVOC EIC-2406 industrial computer and three ultrasonic plate cards, including data acquisition card PR401, 8 bits 100M A/D converter card, integrated timing control and filter card TCF6401, also products of the U.S. Pan-Pacific Automation Instrument Corporation, was used in this automated testing system. The experimental ultrasonic signals for crack detection are obtained by an A-scan with a sampling frequency of $100 \mathrm{MHz}$.

\subsection{Detection Process}

When the equipment commissioning is completed, the console is activated while the water is supplied to the water tank. Then the pipe feeding device begins to send the pipe to the left side of the water tank to start detection. If there is a flaw surpassing the threshold in the pipe, the alarm instrument connecting the probe having detected the flaw raises the alarm. The delay unit of the instrument remembers this flaw signal simultaneously. When the spot of the flaw arrives at the position where the marking gun locates, the delay unit sends out the stenciling signal and makes the marking gun work by PLC's actuation, painting a mark in the spot of the flaw.

\subsection{Software Design}

The system uses a hierarchical modular approach to design defects PMB module. The module structure design based on object-oriented methods, code reuse, scalability and portability is improved. Interactive interface and function modules are designed separately. To use functional modules provide the interface to support user interface.

1) System software development environment

This system uses Visual $\mathrm{C}++$, an integrated development environment, as the development platform. Visual $\mathrm{C}++$ is developed based on the Windows environment with a simple and efficient $\mathrm{C}++$ compiler. It can provide rich visual programming methods and 
API function to operate system underlying directly. Using the MFC(Microsoft Foundation Class Library) to write testing software applications can provide a powerful tool for testing software system's GUI、 testing core classes preparation. Data storage and so forth.

2) Overall design of software systems

The system is developed based on the Windows 2000 system, application software in the topmost layer of the software system. Access and control other hardware devices by calling the Windows 2000 system function. The overall framework of the software is shown in Figure 10.

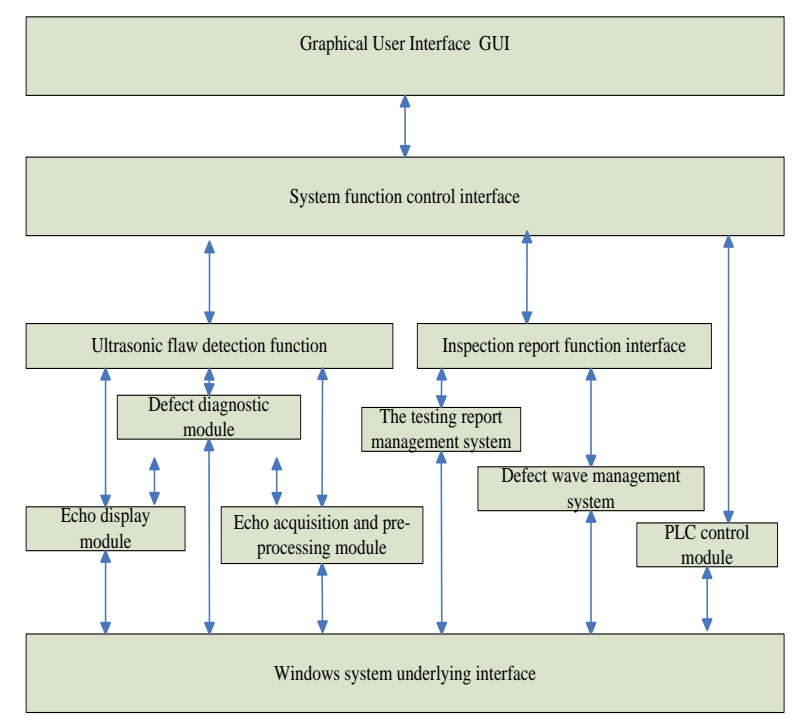

\section{Figure 10. The Overall Framework of the Software}

The main functional modules of the software include: echo acquisition and preprocessing module, defect diagnosis module, echo display module, PLC control module, report management module defect wave management module, the software flow chart is shown in Figure 11. 


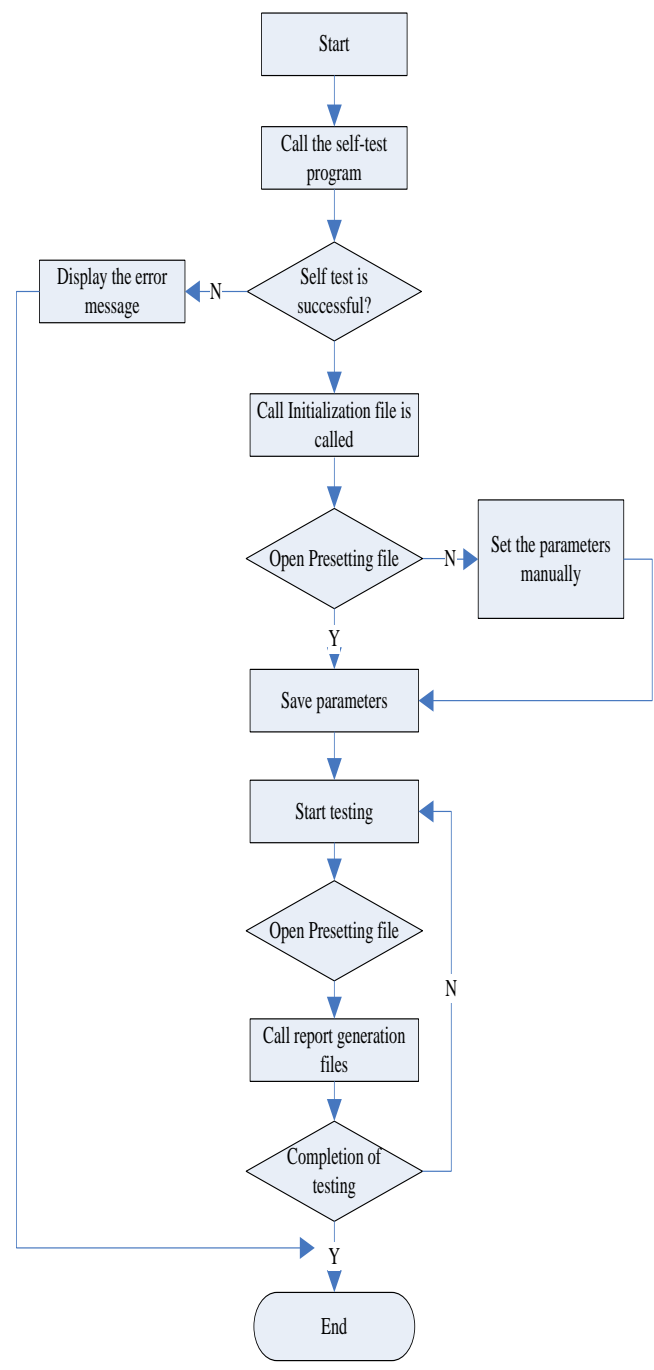

Figure 11. Software Flow Chart

\section{Experiment Results and Analysis}

\subsection{Determination of the Testing Process Parameters}

1) Average for Eccentricity of choice

The eccentricity refers to the horizontal distance between the probe acoustic beam axis and the pipe axis, the angle of incidence of the probe $\alpha$ having something to do with the eccentricity $x$, the angle of incidence $\alpha$ being proportional to the eccentricity $x$, So we can control the size of the angle of incidence by controlling the size of the eccentricity.

$$
\frac{C_{L \text {-water }}}{C_{L \text {-steel }}} \cdot \mathrm{r}<X \leq \frac{C_{L \text {-water }}}{C_{S \text {-steel }}} \cdot \mathrm{r}
$$

By it we can get the eccentricity of pipe with $\Phi 20 \times 6 \mathrm{~mm}$ (shown in Table 1). 


\section{Table 1.The Eccentricity}

\begin{tabular}{|c|c|}
\hline Pipe specifications & $\Phi 20 \times 60 \mathrm{~mm},=10, \mathrm{r}=4$ \\
\hline The eccentricity $(\mathrm{mm})$ & $1.00-1.83$ \\
\hline $\begin{array}{c}\text { The central } \\
\text { eccentricity }(\mathrm{mm})\end{array}$ & 1.42 \\
\hline
\end{tabular}

2) Choice of the water layer thickness

In the water immersion method, the water layer thickness $H$ is greater than $1 / 2$ Full sound path of the Transverse wave in the pipe, $H>x_{s}$.

$$
H>\frac{C_{L \text {-water }}}{\mathrm{C}_{\text {S-steel }}} \times \sqrt{\mathrm{R}^{2}-\mathrm{r}^{2}}
$$

By it we can get the water layer thickness of pipe with $\Phi 20 \times 60 \mathrm{~mm}$, shown in Table 2 .

\section{Table 2.The Water Layer Thickness}

\begin{tabular}{|c|c|}
\hline Pipe specifications & $\Phi 20 \times 60 \mathrm{~mm},=10, \mathrm{r}=4$ \\
\hline $\begin{array}{c}\text { the } \text { water layer } \\
\text { thickness }\end{array}$ & 10.1011 \\
\hline
\end{tabular}

3) Choice of the focal length

The system uses a focused probe to ultrasonic testing. In order to make the ultrasonic energy reaches a maximum, the focus of the probe should be fallen into the tube center line which is perpendicular to the axis of the speed of sound, shown in figure 12.

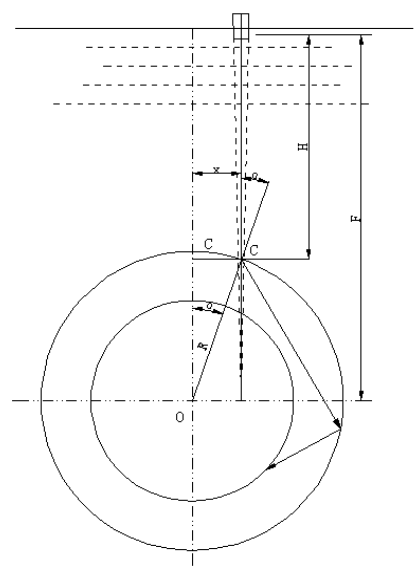

Figure 12. Choice of the Focal Length

In the $\triangle O A B, \quad \mathrm{OA}=\mathrm{R}, \quad \mathrm{OB}=\mathrm{F}-\mathrm{H}$, so :

$$
\begin{gathered}
F=H+\sqrt{R^{2}-x^{2}} \\
F=H+\sqrt{R^{2}-\frac{C_{L \text {-water }}^{2}}{C_{S \text {-steel }}^{2}} \cdot r^{2}}
\end{gathered}
$$

By (13) we can get the focal length of pipe with $\Phi 20 \times 60 \mathrm{~mm}$, shown in Table 3 . 
Table 3.The Water Layer Thickness

\begin{tabular}{|c|c|}
\hline Pipe specifications & $\Phi 20 \times 60 \mathrm{~mm}, \quad=10, \mathrm{r}=4$ \\
\hline the focal length $(\mathrm{mm})$ & 14.10 \\
\hline
\end{tabular}

\subsection{System Testing}

We carry on the equipment (shown in figure.13) commissioning and the flaw detection by using the above principle and equipment to $\Phi 20 \times 6$ (diameter is $20 \mathrm{~mm}$, wall thickness of $6 \mathrm{~mm}$ ) steel pipes. The system selects $5 \mathrm{MHz}$ probe, which is a line focusing probe with $20 \mathrm{~mm}$ focal lengths. The parameters of crack detection are: $1.45 \mathrm{~mm}$ eccentricity of the probe, $10 \mathrm{~mm}$ water distance (this value guaranteed the flaw echo is located between first boundary ultrasonic wave and second ultrasonic boundary wave). Based on these parameters of crack detection actual result obtained in experiment is shown in Figure 14-17.Through the of fig. 14 to Figure 17 , we can find that the defects existing in the pipe can be inspected effectively.

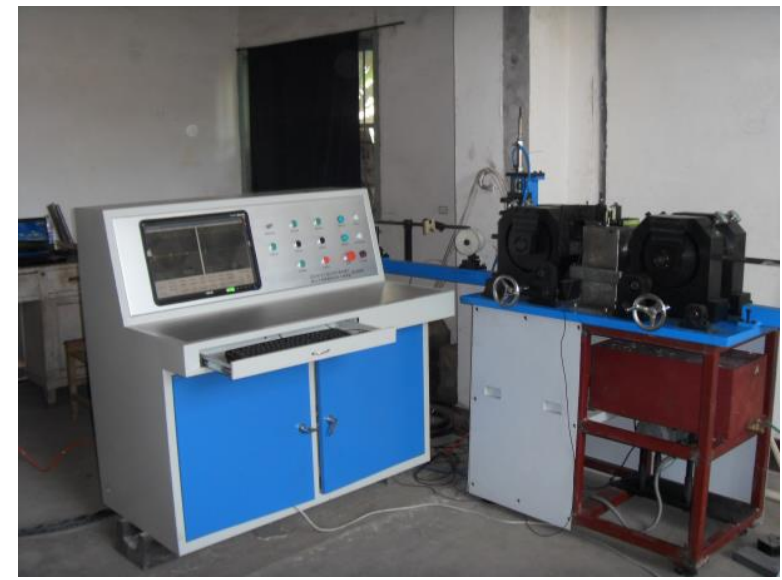

Figure 13. Actual Testing Equipment

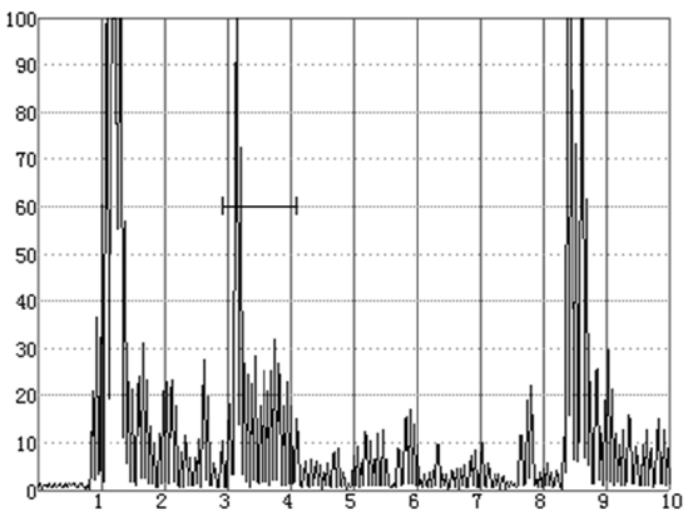

Figure 14. Vertical Inner Wall Flaw Echo of Pipe $(\Phi 20 \times 6)$ 


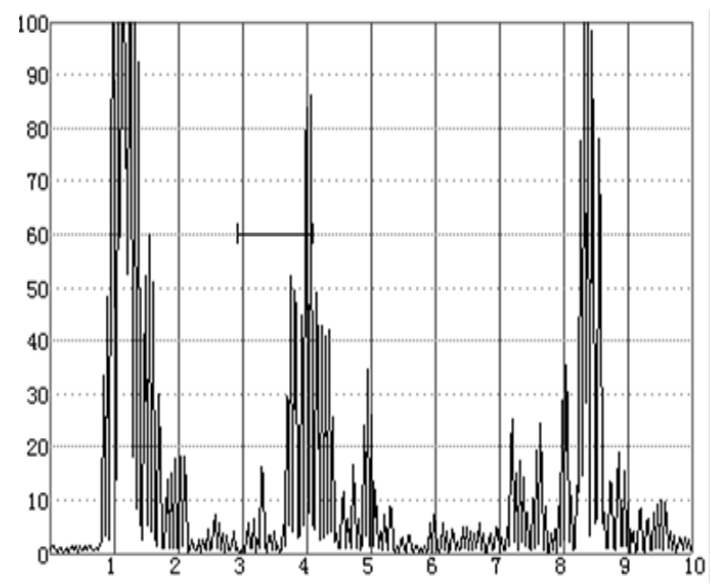

Figure 15. Vertical Outer Wallflaw Echo at Point E of Pipe (\$20×6)

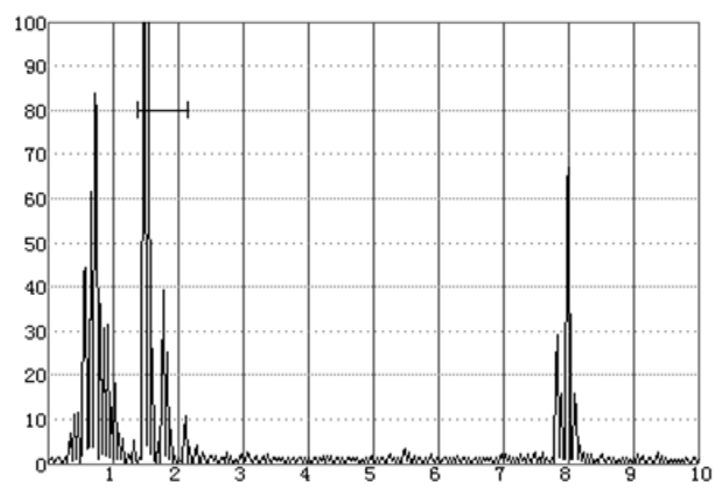

Figure 16. Horizontal Inner Wall Flaw Echo of Pipe $(\Phi 20 \times 6)$

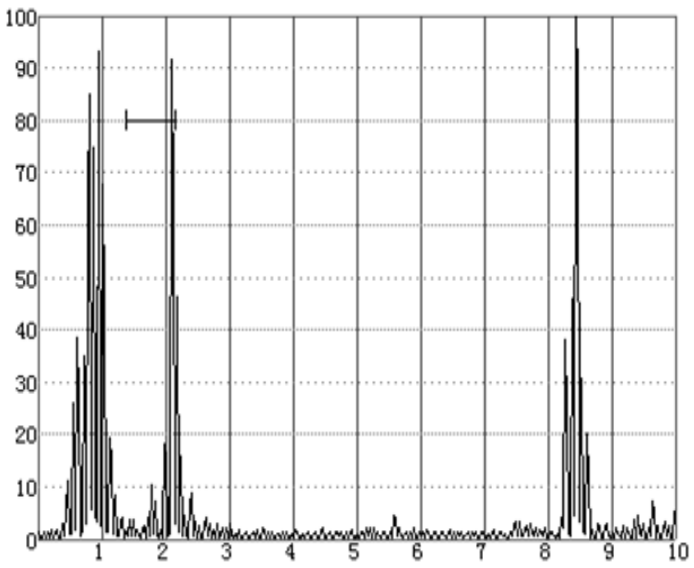

Figure 17. Horizontal Outer Wall Flaw Echo of Pipe $(\Phi 20 \times 6)$ 


\section{Conclusions}

1. This paper introduces the general design scheme of ultrasonic automatic flaw detection system for the thick-walled steel pipe. Ultrasonic automatic flaw detection system is composed of a multi-channel ultrasonic flaw detector and a mechanical drive system. Ultrasonic immersion testing was adopted.

2. The digital pulse echo ultrasonic inspection system, based on the industrial PC and dedicated to ultrasonic flaw detection system for thick-walled steel pipe, was set up. It was composed of hardware system and software system.

3 . We have worked out the testing equipment based the proposed way. According to the results of experiments, the defects can be inspected effectively by using the designed system, so the ultrasonic inspection technology of thick-walled steel pipe was established. Also the designed system has the features of high atumation and high reliability.

\section{Acknowledgments}

This project is supported by the Foundation of PANZHIHUA CITY of China (Grant No. 2013TX-8).

\section{References}

[1] X. Zheng, L. Hou,Y.L. Wang and Y.Q. Yang, "The ultrasonic inspection system of thick-walled seamless steel pipe", Machinery design \& Manufacture, no.7, pp. 90-12, (2011).

[2] L. Piotrowski, B. Augustyniak and M. ChmielewskI, "On the possibility of the application of magnet oacoustic emission intensity measurements for the diagnosis of thick-walled objects in the industrial environment", Measurement Science \& Technology, vol.21, no.3, (2010), pp.035702.

[3] X.G. Li, C.Y. Miao, W. Wang and Y. Zhang, "Fault Automatic Detection Method for Steel Cord Conveyor Belt Based on the Regularity Analysis", JDCTA: International Journal of Digital Content Technology and its Applications, vol. 6, no. 1, (2012), pp. 226 - 234.

[4] G.T. Shen and W.L. Zhang, "A Review of Nondestructive Testing Techniques for Pressure Vessels", Nondestructive Testing, vol. 26, no. 1, (2004), pp. 37 - 40.

[5] R.B. Thompson and D.O. Thompson, "Ultrasonic in nondestructive evaluation", Proceedings of the IEEE, vol. 73, no. 12, (1985), pp.1716- 1755.

[6] T.J. Case and R.C. Waag, "Flaw identification from time and frequency features of ultrasonic waveforms", IEEE Transactions on Ultrasonics, Ferroelectrics and Frequency Control, vol.43, no.4, (1996), pp. 592-600.

[7] H. Yao, T. Feng, R.H. Zhao and G.M. Yu, "Research on Ultrasonic Test Method for Steel Pipe with Heavy Thickness Used in Drill Collar", Welded Pipe and Tube, vol. 32, no. 12, (2009), pp.36-39.

[8] J.L. Rose, "Ultrasonic Waves in Solid Media", Cambridge University Press, ENGLSIH, (1999).

[9] K. Xu, D. Wei, L.N. Yang, X. X. Tian and X.M. Yi, "Discussion on ultrasonic water immersion method for small diameter steel pipe", Welded Pipe and Tube, vol. 35, no. 1, (2012), pp.65-67.

\section{Authors}

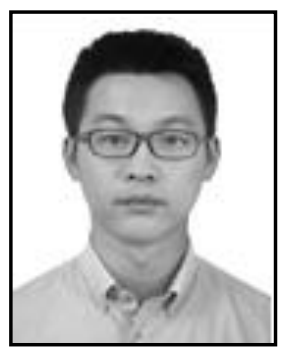

Qi Zhang, he was born in 1986 in China. He has obtained B.E (mechanical design-manufacture and its automation) and M.E (Mechanical design and theory) degrees in 2009 and 2012 respectively from Panzhihua University and Sichuan University. His areas of interest include Servo Control, Robotics, Nondestructive testing and signal de-noising. Currently, he is working as a lecture in School of Machinery and Engineering of Pazhihua University; he also is a $\mathrm{PhD}$ candidate of Sichuan University (Mechanical design and theory) of Sichuan University. E-mail: pzhuzq@126.com. 

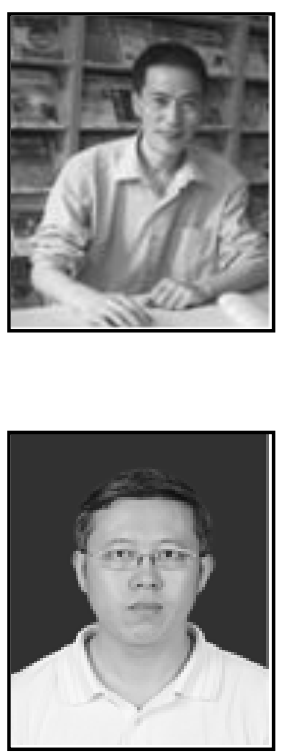

Li Hou, he was born in 1956 in China. He obtained M.E Degree (Mechanical design and theory and PHD degree (mechanical design-manufacture and its automation)) in 1992 and 2000 respectively from Chong Qing University and Sichuan University. His areas of interest include Mechanical transmission, Robotics, mechatronics, Nondestructive testing. Currently, he is working as Professor in School of Manufacturing Science and Engineering, Sichuan University. E-mail: houli4@163.com.

Rui Tang, he was born in 1974 in China. He has obtained B.E (mechanical design-manufacture) and M.E (Mechanical design and theory) degrees in 1997 and 2006 respectively from Lan Zhou University of Technology and Sichuan University. His areas of interest include Robotics, Non-destructive testing and signal de-noising. Currently, he is working as a professor in School of Machinery and Engineering of Panzhihua University; he also is a PhD candidate of Sichuan University (Mechanical design and theory) of Sichuan University. E-mail: pzhutr@163.com. 